\title{
O que faz de "Minsk" e "Luciana" livros para crianças: concepções de infância e leitura em projetos editoriais
}

\section{What makes "Minsk" and "Luciana" books for children: conceptions of childhood and reading in editorial projects}

https://doi.org/10.34112/2317-0972a2020v38n78p115-129

\author{
FabÍOLA Ribeiro Farias ${ }^{1}$ \\ Luiz Percival Leme Britto ${ }^{2}$ \\ Zair Henrique Santos ${ }^{3}$
}

Resumo: O texto apresenta os contos “Minsk" e "Luciana”, de Graciliano Ramos, publicados originalmente no livro Insônia (1947), e discute sua publicação como livros para crianças, a partir da análise de categorias como ilustrações, projeto gráfico e elementos paratextuais, além de representações de infância e concepções de leitura implícitas para a recepção. Conclui que as ilustrações, potencializadas e articuladas pelo projeto gráfico, incluindo a diagramação, são o elemento central na caracterização do livro infantil, e, ainda, que temas à primeira vista aparentemente inadequados ou apenas estranhos para crianças ganham novos contornos com propostas editoriais sustentadas em uma concepção de leitura para a infância.

Palavras-chave: Literatura infantil; leitura; Graciliano Ramos.

AвStRAct: The paper presents the stories "Minsk" and "Luciana" by Graciliano Ramos, originally published in the book Insônia (1947), and discusses its publication as children's books, from the analysis of categories such as illustrations, graphic design and paratextual elements, as well as childhood representations and implicit reading conceptions for reception. It concludes that the illustrations, enhanced and articulated by the graphic design,

1. Centro Federal de Educação Tecnológica de Minas Gerais, Belo Horizonte, Minas Gerais, Brasil.

2. Universidade Federal do Oeste do Pará, Santarém, Pará, Brasil.

3. Universidade Federal do Oeste do Pará, Santarém, Pará, Brasil. 
O que faz de "Minsk" e "Luciana" livros para crianças: concepções de infância e...

including the layout, are the central element in the characterization of the children's book. Yet, what at first glance seemingly inadequate or just unfamiliar themes to children gain new contours with editorial proposals grounded in a conception of reading for childhood. KeYwords: Children's literature; reading; Graciliano Ramos.

\section{INTRODUÇÃO}

Nas últimas décadas, em seu constante processo de reinvenção, o mercado editorial brasileiro, seguind o tendências internacionais, vem demonstrando considerar a criação de edições para crianças de textos de autores consagrados um bom nicho de trabalho. Mais que um recorte de mercado, o que com certeza é, a publicação de textos clássicos em projetos editoriais que, em tese, dialoguem com crianças e adolescentes, movimenta editores, ilustradores, pesquisadores, professores e bibliotecários, além, é claro, de crianças e adolescentes.

Bons exemplos que ilustram esse movimento editorial são obras de escritores inicialmente publicadas para leitores adultos, como, dentre muitas outras, $O$ delírio, de Machado de Assis, que apresenta integralmente o sétimo capítulo de Memórias póstumas de Brás Cubas, ilustrado por Marilda Castanha; a coleção de contos de Gabriel García Márquez, com ilustrações de Carme Solé Vendrell ${ }^{4}$; As margens da alegria, conto de Guimarães Rosa ilustrado por Nelson Cuz; Santiago, poema de Federico García Lorca, com ilustrações de Javier Zabala; Berimbau e outros poemas, antologia de poemas de Manuel Bandeira, organizada por Elias José e com ilustrações de Graça Lima.

No que toca à literatura brasileira, um dos casos mais exemplares é a publicação de textos de Graciliano Ramos para crianças, especialmente porque o autor não se dedicou, de maneira significativa, a escrever para esse público. Embora há quem considere as histórias de Alexandre e outros heróis ${ }^{5}$ e até mesmo o texto "Pequena

4. María dos Prazeres; A luz é como água; O verão feliz da senhora Forbes; Um senhor muito velho com umas asas enormes; A última viagem do navio fantasma; A sesta de terça-feira, originalmente publicados nos livros Doze contos peregrinos, A incrível e triste história de Cândida Erêndira e sua avó desalmada e Os funerais da Mamãe Grande, todos pela editora Record.

5. A aproximação com o público infantil se deve ao caráter popular, normalmente associado ao interesse e ao gosto das crianças, das narrativas que compõem o livro. 
história da República" ${ }^{\prime \prime}$ obras destinadas aos pequenos ${ }^{7}$, apenas $A$ terra dos meninos pelados, que em 1937 recebeu, sob pseudônimo, o terceiro lugar do Prêmio de Literatura Infantil do Ministério da Educação, foi escrito com essa intenção.

Apesar da quase inexistente atenção à escrita para crianças, algumas das obras do autor vêm ganhando projetos editoriais que dialogam com esse público, tornando-se "livros infantis". Para além de Raimundo e dos meninos de olhos coloridos que encontra em Tatitpurun, as histórias de Alexandre e Cesária, já comuns em salas de aula e bibliotecas escolares, porque associadas ao público infantil e juvenil, também contam com novos projetos, com ilustrações e formatos que visam despertar $o$ interesse de crianças e adolescentes.

Entre os livros de Graciliano Ramos nesse contexto, chamam a atenção dois títulos, Minsk e Luciana, publicados originalmente no livro de contos Insônia, cuja primeira edição data de 1947. Por serem estranhos ao universo infantil, em função de sua edição original e em circulação e, ao mesmo tempo, se apresentarem em projetos editoriais criativos no formato para crianças, Minsk e Luciana permitem compreender o que faz de um livro um produto infantil, que é o propósito deste artigo: apresentar e discutir os elementos que transformam textos escritos para adultos em livros para crianças.

Tendo isso em vista, a reflexão proposta será feita a partir da análise dos temas das narrativas, ilustrações, projetos gráficos e elementos paratextuais, além, é claro, de representações de infância e concepções de leitura implícitas para a recepção de Minsk e Luciana.

Vale ressaltar, contudo, que a distinção entre textos e livros para crianças e para adultos se faz apenas para servir à discussão proposta, não sendo esta reflexão aprofundada no âmbito deste trabalho. Ainda que, considerando os extremos, haja publicações evidentemente infantis e outras exclusivamente adultas, reconhece-se uma zona intermediária significativa, fazendo-se distinção, quando é o caso, em função das temáticas e dos tratamentos que lhes são oferecidos, do projeto editorial - que imprime certa legibilidade - e da nomeação mesma do destinatário.

6. Na crônica "Prêmios", publicada em Linhas tortas (RAMOS, 1989), Graciliano Ramos menciona um concurso promovido pela revista Diretrizes para textos destinados às crianças sobre uma história da República. Embora tenha escrito o texto com a intenção de participar de tal concurso, o autor desistiu e não o inscreveu (SANDES, 2011).

7. Desde sua primeira edição, em 1962, Alexandre e outros heróis reúne, além das quatorze histórias de Alexandre, "A terra dos meninos pelados" e "Pequena história da República", o que nos permite uma associação das obras ao público infantil. 
O que faz de "Minsk" e "Luciana" livros para crianças: concepções de infância e...

Ademais, há que se levar em conta a concepção de criança e adolescente e a pedagogia voltada para eles em diferentes momentos históricos, uma vez que aí se estabelecem marcos do que e como esse público deve ler. Henriqueta Lisboa, em sua "palavra ao educador", que introduz o livro Poemas para a Infância, publicado nos anos de 1970, explica que

A seleção desta coletânea obedeceu ao desejo de servir à educação, dentro do campo de interesse da própria infância, buscando temas e assuntos que lhe são familiares: influência musical, vocabulário acessível, variedade de imagens, estrutura singela (LISBOA, 2001, p. 11).

Em seguida, adverte:

Cabe ao educador a tarefa de facilitar o convívio lírico, sem sentimentalismo ocioso, com delicadeza, vivacidade, simpatia e segurança. Para tanto, há de estar certo de que um poema é um objeto de qualidade definida, que não deve ser transformado em linguagem comum para ser aprendido, mas sim, conservado em seu todo para ser compreendido (LISBOA, 2001, p. 11).

Percebe-se, portanto, na perspectiva da poeta-educadora, uma clara concepção de arte, de educação e de infância. Sua antologia e a reflexão que a introduz evidenciam que, sim, há uma arte que se faz própria para a infância, mas que não é óbvia nem banal e muito menos de fácil distinção com relação ao que seria a arte própria para o adulto. O que viria a ser um elemento diferenciador, fruto do desenvolvimento editorial e de novas dinâmicas de comunicação gráfica, é exatamente o projeto gráfico-editorial, objeto de consideração deste artigo.

\section{"LuCiAnA" E "Minsk": os contos}

Luciana é uma menina audaz e brejeira. Quer ser grande, estar entre adultos, circular pela cidade. Até lida com a morte, mas não suporta passar por uma poça de lama em uma rua sem paralelepípedos. A pequena habita dois dos contos de Insônia, publicado por Graciliano Ramos em 1947.

"Luciana" narra a história de uma menina que quer ser grande e ganha do tio Severino, "homem considerável", a autorização de que precisava para sustentar sua 
fantasia: “- Esta menina sabe onde o diabo dorme" (RAMOS, 1987, p. 63). Andando na ponta dos pés, no ombro uma caixa de papelão pendurada com cordões e nas mãos um pedaço de pau a título de sombrinha, a menina se transformava na imaginária $\mathrm{D}$. Henriqueta da Boa Vista. Entre idas e vindas à sala onde os pais recebiam tio Severino, e desdém pela irmã, Maria Júlia, com suas bonecas e revistas, o leitor é apresentado à menina que foge de casa pela janela, ganha as ruas da cidade e é sempre resgatada pelo Seu Adão carroceiro. Aliás, é ele, Seu Adão, em sua negritude, que coloca em xeque a única informação segura que Luciana tinha sobre o diabo: a de que era preto e possuía chifres e rabo, sendo que chifres e rabo serviam apenas para que o diabo não ficasse reduzido a um brinquedo ordinário:

Certamente o diabo tinha gênio ruim, em horas de zanga batia nas pessoas com o rabo, espetava-as com os chifres. E retinto, da cor de Seu Adão carroceiro. Mas Seu Adão era bom, Seu Adão era ótimo: quando via crianças chorando extraviadas, recolhia-as, contava histórias lindas, ria mostrando os dentes alvos (RAMOS, 1987, p. 65).

Ainda que não tivesse clareza sobre quem era e como seria o diabo, ouvir que sabia onde ele dormia e perceber alguma intimidade com algo que extrapolava o universo infantil dava a Luciana uma distinção e também a constrangia diante das lembranças do dia anterior, em que por pirraça acabou sentada em um poça de lama no meio da rua e recebera três palmadas da mãe.

"Minsk" traz ao leitor as mesmas personagens de "Luciana". Luciana se apaixona pelo periquito que ganhou do tio Severino e, sorteando um lugar no mapa, batiza-o pelo nome apontado por seu dedo, lido pela irmã Maria Júlia e confirmado por sua mãe: Minsk.

A chegada do periquito modificou a menina, que já não fugia pela janela e deixara de lado D. Henriqueta da Boa Vista e suas amigas imaginárias; agora, seu tempo era dedicado a Minsk, com quem passava o dia e saía em sua busca se seus passeios pelas copas das mangueiras e pela vizinhança demorassem mais que o comum.

É uma das brincadeiras da menina, andar com os olhos fechados e de costas, que põe fim à história entre Luciana e Minsk.

Um dia em que marchava assim pisou num objeto mole, ouviu um grito. Levantou o pé, sentindo pouco mais ou menos o que sentira ao ferir-se num caco de vidro. Virou-se, alarmada, sem perceber o que estava acontecendo. Havia uma desgraça, com certeza 
O que faz de "Minsk" e "Luciana" livros para crianças: concepções de infância e...

havia uma desgraça. Ficou um minuto perplexa, e quando a confusão se dissipou, sacudiu a cabeça, não querendo entender (RAMOS, 1987, p. 75-76).

Diante de uma "trouxa de penas ensanguentadas", a menina se vê diante da fatalidade da morte, com "um bolo na garganta, peso imenso por dentro, qualquer coisa a rasgar-se, a estalar” (RAMOS, 1987, p. 76).

LUCIANA E MINSK: OS LIVROS PARA CRIANÇAS

Os livros Minsk e Luciana foram publicados, respectivamente, em 2013 e 2015, pela editora Galerinha, um dos selos infantis do grupo editorial Record. Ambos apresentam os contos em texto integral, tal como publicados em Insônia, sem qualquer alteração ou adaptação. Em sua ficha catalográfica, elemento paratextual que classifica os livros no que toca à área de conhecimento em que se inserem, orientando a que público se destinam, Minsk foi classificado como "literatura infantojuvenil brasileira" e Luciana como "romance infantil brasileiro", o que, mutatis mutandis, os coloca nas mesmas estantes em bibliotecas e livrarias, tendo como prováveis leitores as crianças e adolescentes.

Os elementos paratextuais dizem muito sobre os textos publicados, de maneira geral em formato de livro, e estabelecem sua identidade, apresentando informações sobre sua publicação e orientando sua circulação:

Esses traços descrevem, essencialmente, suas características espaciais, temporais, substanciais, pragmáticas e funcionais. De maneira mais concreta: definir um elemento de paratexto consiste em determinar seu lugar (pergunta onde?), sua data de aparecimento e às vezes de desaparecimento (quando?), seu modo de existência, verbal ou outro (como?), as características de sua instância de comunicação, destinador e destinatário (de quem? a quem?) e as funções que animam sua mensagem: para fazer o quê? (GENETTE, 2009, p. 12).

Essas informações são compreendidas pelo autor em duas perspectivas: os elementos peritextuais são aqueles que fazem parte do texto publicado no espaço mesmo do volume impresso ou eletrônico (informações autorais, data e local de edição, prefácio, posfácio, apresentação, dentre outros); os epitextuais são os que apresentam ou falam do texto publicado fora de seu espaço, como textos de crítica e divulgação publicados na imprensa, entrevistas com o autor, dentre outros. 
A capa e a quarta capa são os primeiros contatos dos leitores com os livros e costumam trazer suas principais informações peritextuais. Na capa, o mais usual é a apresentação do título da obra, seu autor e selo editorial, além de imagens que compõem sua identidade visual. De maneira geral, a quarta capa tem como objetivo apresentar o livro aos leitores, despertar seu interesse pela obra, apresentando excertos, breves apreciações críticas ou informações sobre autoria.

As capas de Minsk e Luciana apresentam autores (escritor e ilustradora), título, selo editorial e ilustração; na quarta capa os textos dos dois livros são distintos em sua natureza. No primeiro, há a sinopse da narrativa, em linguagem direta, dirigindo-se a leitores de histórias, uma vez que é no enredo, na história a ser contada, que está a estratégia de atração de possíveis leitores, sejam crianças ou adultos que leiam para elas. Como não está assinado, podemos supor que foi escrito pela equipe editorial. Vale destacar que, abertas, capa e quarta capa, unidas pela ilustração, formam uma página dupla, como um cartaz que anuncia, com texto e imagens, a história a ser contada. Em Luciana, a quarta capa apresenta um fragmento do conto, que só pode ser percebido como tal após a leitura integral do texto, uma vez que não há a sinalização de que é parte da obra e nem mesmo a assinatura do autor. Em ambos, as orelhas do livro trazem informações biográficas e literárias sobre Graciliano Ramos e Rosinha.

Suas características materiais obedecem ao que vem sendo praticado em livros para crianças. Minsk tem formato alargado, com a altura maior que a largura, retangular, medindo $19 \times 28 \mathrm{~cm}$. Impresso em papel offset $120 \mathrm{~g} / \mathrm{m}^{2}$, tem gramatura mais espessa que a usual na impressão de livros destinados ao público adulto, normalmente em torno de $90 \mathrm{~g} / \mathrm{m}^{2}$. Luciana tem o formato quadrado, medindo $24 \mathrm{X} 24 \mathrm{~cm}$, e foi impresso em papel couché fosco $150 \mathrm{~g} / \mathrm{m}^{2}$. Os livros têm, cada, 32 páginas.

Ambos foram ilustrados por Rosinha, ilustradora pernambucana de considerável reconhecimento da crítica especializada na produção editorial brasileira destinada a crianças e jovens, que, além de ilustrar textos de diversos escritores, publica trabalhos autorais.

As ilustrações que compõem Minsk são marcadas por cores fortes e as imagens - a menina, o periquito, a mãe - ocupam quase a totalidade do espaço das páginas, com muitos desenhos em que seus rostos são mostrados em "close", criando sensação de proximidade com o leitor. O livro é, em grande parte, composto por páginas duplas, em que texto e imagem ocupam de maneira integrada duas páginas, desconsiderando o limite de cada uma delas e ocupando-as como se fossem única. O texto, em tipologia Sentinel \& Poster Bodoni, tem como fundo, com exceção de 
O que faz de "Minsk" e "Luciana" livros para crianças: concepções de infância e...

duas páginas, a parte da página em branco. Chama a atenção o destaque, marcado pelo recurso de negrito, de algumas frases do texto, que parecem se relacionar com a ilustração da mesma página, propondo uma espécie de equivalência entre texto destacado e imagem, direcionando o leitor e interferindo na leitura.

Seu projeto gráfico e diagramação, assinados por Angelo Allevato Bottino, alteram a disposição do texto, originalmente publicado com apenas uma ilustração e sem interferência direta na narrativa, impactando na cadência da leitura. $\mathrm{Na}$ diagramação, alguns dos parágrafos foram fragmentados, com aparente intenção de criação de episódios dentro da história, marcada pela presença de adornos coloridos nas letras iniciais capitulares, como em iluminuras. Esse artifício parece atender a um propósito implícito de facilitação da leitura para crianças e adolescentes, criando uma espécie de pausa, de ritmo marcado pela virada da página. Vale destacar que o último parágrafo do texto ocupa a parte inferior, em branco, da última página do livro, propondo, imageticamente, uma espécie de epílogo, seguido pela palavra FIM, inexistente no conto de Graciliano Ramos. O livro parece entender ser necessário dizer às crianças, suas leitoras, que a história acabou. Chama a atenção, ainda, a numeração das páginas, que é marcada de maneira aleatória, sem qualquer traço de regularidade (em todas as páginas ou apenas em páginas pares ou apenas em páginas ímpares...), presente apenas onde há espaços em branco na parte inferior da página.

As imagens de Luciana também são marcadas por cores fortes, em uma combinação impactante de amarelo, laranja, marrom e rosa, em tons terrosos. Não há, no colofão, informação da tipologia utilizada. As cores de fundo em que o texto é impresso são ora o branco, ora coloridas, sendo que nas últimas a cor apresenta leves texturas, criando a impressão de fluidez e continuidade com as ilustrações e, em uma delas, prejudicando a legibilidade do texto (fundo em dois tons de rosa com letras na cor branco). Seu projeto gráfico (criação de capa e diagramação de miolo, como especificado na ficha técnica do livro), de autoria de Igor Campos, explora as cores preponderantes na ilustração, remetendo ao universo nordestino do escritor e da ilustradora. Como em Minsk, os parágrafos maiores do texto original são fragmentados, na mesma lógica de criação de episódios.

É importante observar que, apesar de terem como protagonista a mesma personagem - a menina Luciana - e sido originalmente publicados em Insônia, em sequência, não há nos livros qualquer informação que os vincule ou que informe ao leitor sobre a existência de um e outro. Nem mesmo as ilustrações, de autoria 
da mesma ilustradora, ou a proposta editorial, concretizada em seu projeto gráfico e materialidade, propõem identidade entre os dois livros, uma vez que seus formatos, diagramação e imagens da menina são distintos. Chama a atenção, ainda, a ausência da informação de que os contos foram publicados originalmente em uma coletânea, junto com outros contos.

Embora não se apresentem no espaço mesmo da publicação, os epitextos são importantes na construção do lugar público do livro. Os textos publicados na imprensa impressa e eletrônica (jornais, revistas, blogues), propagados nas redes sociais e nos veículos especializados contribuem para a divulgação dos livros para seus possíveis públicos, além de validar a intenção editorial dos mesmos. Com pouca presença na imprensa, a produção crítica acerca dos livros para crianças, quando publicada, se resume, de maneira geral, a sinopses dos enredos. No caso específico de Minsk e Luciana, as matérias veiculadas pela imprensa se dedicaram a celebrar a oferta de um autor consagrado, Graciliano Ramos, para o público infantil, eximindo-se de qualquer apreciação de sua realização editorial e até mesmo da correção das informações apresentadas - em algumas das matérias, Minsk e Luciana são apresentados como textos infantis do autor, agora publicados com ilustrações. Embora haja menções às ilustrações, as mesmas são entendidas apenas como elemento do universo infantil, e não como elemento narrativo ${ }^{8}$.

\section{LUCIANA E MINSK: AS CRIANÇAS E A LEITURA}

Pensar, falar, escrever, ilustrar e editar livros para crianças, literários ou não, tem como ponto de partida, nem sempre de forma explícita, uma concepção de infância que contempla vários aspectos, desde como os pequenos leem até os temas mais adequados para a criança, de maneira geral idealizada, passando por

8. Jornal Correio, da Bahia: "Conto de Graciliano Ramos ganha edição para leitores mirins" (https://www. correio24horas.com.br/noticia/nid/conto-do-escritor-graciliano-ramos-ganha-edicao-para-os-leitoresmirins/); página eletrônica Livre Opinião Ideias em Debate: "Conto infantil de Graciliano Ramos ganha edição ilustrada por Rosinha” (https://livreopiniao.com/2015/11/o3/conto-infantil-de-graciliano-ramos-ganha-edicaoilustrada-por-rosinha/); Diário do Nordeste: “Graciliano Ramos para pequenos” (http://blogs.diariodonordeste. com.br/diarinho/biblioteca-do-diarinho/graciliano-ramos-para-pequenos/); Gazeta de Alagoas: "Minsk mostra olhar infantil de Graciliano" (http://gazetaweb.globo.com/gazetadealagoas/noticia.php?c=235834); Hoje em Dia: “Conto infantil 'Luciana', de Graciliano Ramos, tem reedição” (https://www.hojeemdia.com. $\mathrm{br} /$ almanaque/conto-infantil-luciana-de-graciliano-ramos-tem-reedi\% $\mathrm{C}_{3} \% \mathrm{~A}_{7} \% \mathrm{C}_{3} \% \mathrm{~A}_{30} \mathrm{O}-1.349644$ ). 
O que faz de "Minsk" e "Luciana" livros para crianças: concepções de infância e...

possíveis interesses específicos de cada idade, estímulo do mercado, expectativas dos pais e demandas escolares.

Embora alguns temas sejam recorrentes na criação e na edição de livros para crianças, com forte vinculação à faixa-etária ou a uma pretensa experiência leitora, é difícil identificar com segurança que tipos de histórias ou personagens interessam efetivamente a essa categoria ampla designada "crianças" ou "infância" - ou, na contramão, que temas ou narrativas não interessam a esse público.

A reflexão sobre a infância e o infantil é complexa e pode ser feita a partir de vários campos, sendo produtivo o rompimento de contornos disciplinares para a observação de sujeitos que são, ao mesmo tempo, biológicos, sociais, históricos, econômicos e culturais. No âmbito deste texto, optamos por pensar a infância em uma perspectiva que, ao invés de estabelecer o que as crianças são ou deixam de ser, tem como horizonte sujeitos que nascem em um mundo velho, grande e diverso, com todas as suas contradições, e são convocados, desde pequenos, a organizar e a compreender o tempo, o espaço e as relações que os determinam, ininterruptamente. Isso, é claro, pressupõe crianças e construções de infâncias as mais diversas. Embora amplo e bastante fluido, este entendimento permite questionar a existência de um pretenso universo temático e narrativo que interessa naturalmente às crianças, perguntando-se se essa não é uma construção moral e pedagógica.

Ressalvadas as limitações próprias de cada idade nos mais diversos contextos socioculturais, especialmente em relação à aprendizagem da leitura e ao repertório simbólico de cada criança, na grande maioria das vezes ligadas à forma e às experimentações com a linguagem, não há justificativa consistente para a definição prévia ou a exclusão de uma gama de temas nos livros para as crianças, a título de "infantil". Dito de outra maneira, desde que não haja obstáculos intransponíveis para a compreensão de uma narrativa, tudo e qualquer coisa no mundo pode lhes interessar e tocar diretamente, uma vez que são sujeitos históricos.

No campo literário, assim como em qualquer criação artística, o aspecto determinante para que uma narrativa interesse à criança, assim como ao adulto, é sua elaboração estética e modos de significação, mesmo que isso, em determinado momento, se resuma à compreensão das possibilidades de reelaboração do conhecido, a uma desconfiança, consciente ou não, de que a mesma língua que comunica e ordena, brinca e subverte a ordem estabelecida; à compreensão, ainda, de que, para além de registrar, a língua é potente para recriar o que existe e inventar o que poderia existir. 
Ainda que a construção de sentido, que a fruição e a apropriação de uma obra só se realize na recepção e que esta seja constituída por aspectos subjetivos, o que invalidaria qualquer possibilidade de relação valorativa verificável entre elaboração estética e leitura, é a proposição intencional de reinvenção e apresentação da vida, do mundo e do tempo, por meio de palavras e imagens, que permite às crianças ler ou ouvir uma história como experiência. É preciso ressalvar, naturalmente, que costumam ser classificadas como literárias obras atraentes para o público infantil, embora elas se limitem a contar histórias com personagens conhecidos pelas crianças em função de sua ampla exposição em séries televisivas e mídias veiculadas na internet. Em resumo, a grande questão é com que potência de sentido uma narrativa se apresenta a um leitor, criança ou adulto. De que maneira a poesia, em suas mais diversas construções, convida-nos a experimentar as possibilidades da língua? Como as imagens se transformam em narrativas em um livro sem palavras? Como um conto autoriza a partilha de sentimentos, tempos e espaços inusitados? Como o tempo de uma história expande e torna comum a experiência do nosso próprio tempo?

Em sua edição original, com poucas ilustrações, sem cor e em formato tradicional, em uma coletânea sob o título de Insônia, dificilmente os contos "Minsk" e "Luciana" seriam oferecidos a crianças, a não ser em casos específicos em que pais ou professoras conhecessem e apreciassem o autor, reconhecendo em tais contos a possibilidade de leitura com e para os pequenos, a partir de entendimento da educação literária como processo formativo, e não como histórias oportunas para a disseminação de valores morais, a diversão e o preenchimento do tempo. Mas, de maneira geral, é bem provável que, em função de sua temática e do projeto editorial original em que se apresentam, se propostos pela escola, fossem até mesmo rejeitados, não pelas crianças, mas por quem tutela suas leituras.

Então, o que faz com que os mesmos contos publicados por Graciliano Ramos em 1947, mais de sessenta anos depois, se apresentem no formato de livros infantis? Os temas - a saber, a amizade, a morte, a perda e o luto, em "Minsk", e o desejo de abandonar a infância, de escapar dos muros de casa e do olhar dos adultos, de ser grande, em "Luciana" -, bem como os textos, são os mesmos da publicação original.

Ao que tudo parece indicar, o que transforma os contos em questão em livros para crianças e, portanto, em leituras para o público infantil, são escolhas editoriais que, por sua natureza, nada têm de especificamente infantis, mas que foram assim consolidadas como práticas da edição. 
O que faz de "Minsk" e "Luciana" livros para crianças: concepções de infância e...

Em primeiro lugar, com exceção dos chamados livros de arte (pintura, fotografia, arquitetura) e obras de referências (atlas, dicionários, enciclopédias) e alguns nichos específicos, como culinária, de maneira geral apenas os livros para crianças são impressos em formatos grandes. É bastante rara a publicação de um livro de literatura em formatos grandes.

Em segundo, bastante incomum é a presença de ilustrações na composição da narrativa em livros para adultos, especialmente nos de literatura; quando aparecem em livros não destinados às crianças, as ilustrações costumam se apresentar à parte do texto, como acontece com os desenhos de Axel Leskoschek, em Insônia (no conto Luciana não há ilustrações; Minsk conta com uma ilustração).

Com exceção das imagens utilizadas na capa e, algumas vezes, pequenas vinhetas, na produção editorial brasileira, a não ser em casos em que a narrativa pressupõe imagens, como nas graphic novels, por exemplo, as ilustrações não fazem parte do universo adulto.

O uso de ilustrações com intencionalidade narrativa tem se mostrado marca distintiva na criação atual de livros para crianças, tenham suas histórias predominância de texto escrito ou imagens, ou até mesmo a presença exclusiva de ilustrações. Se na produção editorial mais antiga para o público infantil as ilustrações cumpriam papel de ornamento isolado, hoje, em livros esteticamente mais elaborados, compõem a narrativa, criando pausas e continuidades, oferecendo chaves de leitura complementares e externas ao texto escrito e exigindo dos leitores exercícios mais complexos de ver e ler.

Assim, as ilustrações, potencializadas e articuladas pelo projeto gráfico, incluindo a diagramação, são o elemento central na caracterização do livro infantil. Como demonstrado na análise de Minsk e Luciana, os temas que à primeira vista podem parecer inadequados ou apenas estranhos para crianças ganham novos contornos com propostas editoriais sustentadas em uma concepção de leitura para a infância.

\section{Conclusão}

A análise do processo editorial de produção dos contos "Minsk" e "Luciana", de Graciliano Ramos, como livros para crianças, foi realizada a partir da identificação dos elementos mais recorrentes, explícitos ou não, no que reconhecemos como livros infantis: ilustrações, projeto gráfico, elementos paratextuais, materialidade e concepções de infância e leitura. Constatamos que o projeto editorial, que abarca processos internos e externos ao texto, opera uma espécie de recriação dos textos 
originais, o que possibilita a realização de um produto considerado especificamente infantil e, portanto, inserido no mercado voltado a esse seguimento.

Podemos nos perguntar se as ilustrações e os projetos gráficos que, muitas vezes, reinventam sentidos e criam narrativas, transformando texto e imagens em uma escrita híbrida, são algo destinado exclusivamente às crianças. As prescrições e limitações prévias de projetos editoriais a determinado público são discussões relevantes e necessárias no campo, que ampliam ou restringem possibilidades de leitores e leituras, mas extrapolam a proposição deste texto. O que importa é apontar, a título de conclusão, que, no que toca aos livros Minsk e Luciana, de Graciliano Ramos e Rosinha, são as escolhas editoriais, como ilustrações, projeto gráfico, formato, papel e informações paratextuais que os transformam em produto infantil, no sentido mais estrito da palavra (algo que é produzido; o resultado de uma produção).

\section{REFERÊNCIAS}

ASSIS, Machado de. O delírio: capítulo VII de Memórias póstumas de Brás Cubas. Ilustrações de Marilda Castanha. São Paulo: Companhia das Letrinhas, 2010.

BANDEIRA, Manuel. Berimbau e outros poemas. Ilustrações de Graça Lima. Rio de Janeiro: Nova Fronteira, 2006.

FARIA, Maria Isabel; PERICÃO, Maria da Graça. Dicionário do livro: Da escrita ao livro eletrônico. São Paulo: Editora da Universidade de São Paulo, 2008.

GARCÍA LORCA, Frederico. Santiago. Ilustrações de Javier Zabala. São Paulo: WMF Martins Fontes, 2009.

GARCÍA MÁRQUEZ, Gabriel. A luz é como água. Ilustrações de Carme Solé Vendrell. Rio de Janeiro: Record, 2001.

GARCÍA MÁRQUEZ, Gabriel. A sesta de terça-feira. Ilustrações de Carme Solé Vendrell. Rio de Janeiro: Record, 2001.

GARCÍA MÁRQUEZ, Gabriel. A última viagem do navio fantasma. Ilustrações de Carme Solé Vendrell. Rio de Janeiro: Record, 2001.

GARCÍA MÁRQUEZ, Gabriel. María dos Prazeres. Ilustrações de Carme Solé Vendrell. Rio de Janeiro: Record, 2001.

GARCÍA MÁRQUEZ, Gabriel. O verão feliz da senhora Forbes. Ilustrações de Carme Solé Vendrell. Rio de Janeiro: Record, 2001.

GARCÍA MÁRQUEZ, Gabriel. Um senhor muito velho com umas asas enormes. Ilustrações de Carme Solé Vendrell. Rio de Janeiro: Record, 2001.

GENETTE, Gérard. Paratextos editoriais. Cotia, SP: Ateliê Editorial, 2009.

LAJOLO, Marisa; ZILBERMAN, Regina. Literatura infantil: história \& histórias. São Paulo: Ática, 1994. LISBOA, Henriqueta. Poemas para a infância. Rio de Janeiro: Ediouro, 2001.

RAMOS, Graciliano. Insônia. Rio de Janeiro, São Paulo: Record, 1987. 
O que faz de "Minsk" e "Luciana" livros para crianças: concepções de infância e...

RAMOS, Graciliano. Linhas tortas. Rio de Janeiro, São Paulo: Record, 1989.

RAMOS, Graciliano. Alexandre e outros heróis. Rio de Janeiro, São Paulo: Record, 1991.

RAMOS, Graciliano. Minsk. Ilustrações de Rosinha. Rio de Janeiro: Galerinha Record, 2013.

RAMOS, Graciliano. Luciana. Ilustrações de Rosinha. Rio de Janeiro: Galerinha Record, 2015.

RAMOS, Graciliano. A terra dos meninos pelados. Ilustrações de Jean-Claude Ramos Alphen. Rio de Janeiro: Record, 2016.

ROSA, Guimarães. As margens da alegria. Ilustrações de Nelson Cruz. Rio de Janeiro: Nova Fronteira, 2010.

SANDES, N. F. Memória e história da Primeira República. In: SIMPÓSIO NACIONAL DE HISTÓRIA: ANPUH 50 ANOS, 26, 2011, São Paulo. Anais eletrônicos... São Paulo: USP, jul. 2011. Disponível em: http://www.snh2011.anpuh.org/resources/anais/14/1300662102_ARQUIVO_ Memoria_e_historia_da_PrimeiraRepublica[1].pdf. Acesso em: 10 mar. 2019.

\section{SOBRE OS AUTORES}

Fabíola Ribeiro Farias é graduada em Letras, mestre e doutora em Ciência da Informação pela Universidade Federal de Minas Gerais - UFMG, com estágio pós-doutoral em Educação na Universidade Federal do Oeste do Pará - Ufopa. Integra o Grupo de Pesquisa e Intervenção em Leitura, Escrita e Literatura na Escola - Lelit, da Ufopa.

E-mail: fabirfarias@yahoo.com.br.

Luiz Percival Leme Britto é doutor em Linguística pelo IEL/Unicamp. É professor do Programa de Pós-graduação em Educação da Universidade Federal do Oeste do Pará - Ufopa e coordenador do Grupo de Pesquisa e Intervenção em Leitura, Escrita e Literatura na Escola - Lelit, da Ufopa. Foi presidente da ALB de 1993 a 2006.

E-mail: luizpercival@hotmail.com.

Zair Henrique Santos possui Graduação Plena em Letras (Universidade Federal do Pará, 1997), tem Mestrado em Letras: Linguística e Teoria Literária (Universidade Federal do Pará, 2006) e Doutorado em Doutorado em Educação, na área de concentração: Ensino e Práticas Culturais (Universidade Estadual de Campinas, 2016). É professor/pesquisador da Universidade Federal do Oeste do Pará. Tem experiência na área de Letras e Pedagogia, com pesquisa nos seguintes temas: leitura e escrita; literatura de expressão Amazônica; imaginário popular; 
Educação indígena e quilombola e literatura infanto-juvenil na escola. Além disso, é coordenador adjunto do LELIT-Grupo de estudos, literatura e intervenção em literatura infantojuvenil na escola.

E-mail: zair.santos@ufopa.edu.br.

Recebido em o9 de junho de 2019 e aprovado em 21 de fevereiro de 2020. 